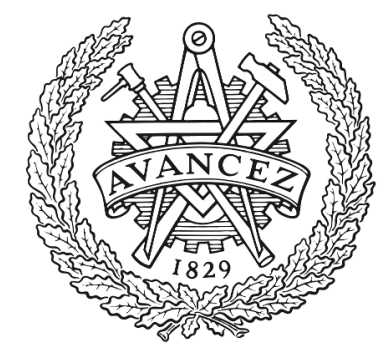

CHALMERS

UNIVERSITY OF TECHNOLOGY

\title{
Concrete subjected to projectile and fragment impacts: Modelling of crack softening and strain rate dependency in tension
}

Downloaded from: https://research.chalmers.se, 2023-04-26 12:56 UTC

Citation for the original published paper (version of record):

Leppänen, J. (2006). Concrete subjected to projectile and fragment impacts: Modelling of crack softening and strain rate dependency in tension. International Journal of Impact Engineering, 32(11): 1828-1841. http://dx.doi.org/10.1016/j.ijimpeng.2005.06.005

N.B. When citing this work, cite the original published paper. 


\title{
Concrete subjected to projectile and fragment impacts: Modelling of crack softening and strain rate dependency in tension
}

\author{
Joosef Leppänen* \\ Department of Structural Engineering and Mechanics, Concrete Structures, Chalmers University of Technology, \\ SE-41296 Göteborg, Sweden
}

Received 6 September 2004; received in revised form 4 March 2005; accepted 13 June 2005

Available online 8 September 2005

\begin{abstract}
This paper deals with modelling of plain concrete in tension. The aim is to improve the accuracy of the numerical analyses for projectile and fragment impacts on concrete. A bi-linear crack softening law and a strain rate-dependent law are implemented in the hydrocode AUTODYN. Parametric studies are made, and numerical analyses are compared with experiments conducted and with experiments found in the literature. The depth of penetration is mainly dependent on the compressive strength of the concrete. However, to correctly model spalling, cracking and scabbing in concrete, the tensile strength, fracture energy, and strain rate in tension are very important. It is shown that the accuracy of the results in the numerical analyses of concrete subjected to projectile and fragment impacts was improved, when using a bilinear softening law and the modified strain rate dependency for tension.
\end{abstract}

(C) 2005 Elsevier Ltd. All rights reserved.

Keywords: Concrete; Projectile and fragment impacts; Numerical modelling; Crack softening; Strain rate in tension

\section{Introduction}

High-velocity impact on concrete structures has been a subject of numerical analyses in recent decades. The main focus has been on modelling the compressive behaviour of concrete.

\footnotetext{
${ }^{*}$ Fax: + 46(0)31 7722260.

E-mail address: joosef.leppanen@sem.chalmers.se.
} 
However, when a compressive stress wave reflects at free boundaries, tensile stress waves are generated. These tensile stress waves may cause scabbing on the side opposite the impact. Spalling also depends on the tensile behaviour of the concrete. In the literature several papers deal with numerical analyses of projectile penetration into concrete, as in Clegg et al. [1], Johnson et al. [2] and Leppänen [3]. The focus in the material modelling for the past few decades has been to improve the compressive behaviour of concrete. The depth of penetration is mainly determined by the compressive pressure and strain rate dependent response of concrete in compression. Fragment impacts have been studied by Leppänen [4], Rempling [5], Papados [6] and Ågardh [7].

This paper examines both projectile impact and fragment impacts by 2D axisymmetric numerical analyses using the smooth particle hydrodynamics (SPH) technique. The RHT model in AUTODYN is used, and it captures realistically the behaviour of concrete in compression, taking into account the pressure dependency and strain-rate effects.

In Leppänen [3], it was shown by parametric studies that the strain rate in tension was of great importance when studying spalling of projectile impacts. Rempling [5] showed that the tensile behaviour is also important in simulating scabbing for fragment impacts. In the RHT model the post-peak response of concrete in tension is modelled by a linear softening law. In the previous work done by Leppänen [3] and Rempling [5], the linear crack softening law was used in the numerical simulations. To get even more accurate results, a bi-linear softening law has been implemented in the hydrocode AUTODYN. Hillerborg [8] introduced a stepwise linear softening law to describe concrete crack softening behaviour. However, a bi-linear softening law proposed by Gylltoft [9] is used in the material model presented in this paper.

In CEB-FIB Model Code 90 [10] a formulation for strain rate dependency is given for tension. However, it was shown by Malvar and Ross [11] that the CEB formulation does not fit very well with the experimental results. They collected experimental data from the literature and modified this formulation of the strain rate dependency. In the work done here, a stepwise linear strain rate law is also implemented in the material model, by which the user can determine the strain rate dependency.

\section{Description of the numerical model}

\subsection{The RHT model in autodyn}

In the numerical analyses, the RHT model was used, and the software was AUTODYN [12]. The governing equations in AUTODYN are the Rankine-Hugoniot equations: the conservation of mass, momentum and energy. To complete the description of the continuum, two additional relations describing the material behaviour are needed: first the equation of state (EOS) and second, a constitutive model. The EOS relates the pressure to the density; the one used in the numerical analyses was chosen from the AUTODYN material library, since no three axial material tests were available. The constitutive model chosen was the RHT one in AUTODYN, developed by Riedel [13]. The model, which consists of three yield surfaces, as shown in Fig. 1, includes pressure hardening, strain hardening and strain rate hardening. Furthermore, the deviatoric section of the surfaces depends on the third invariant. 


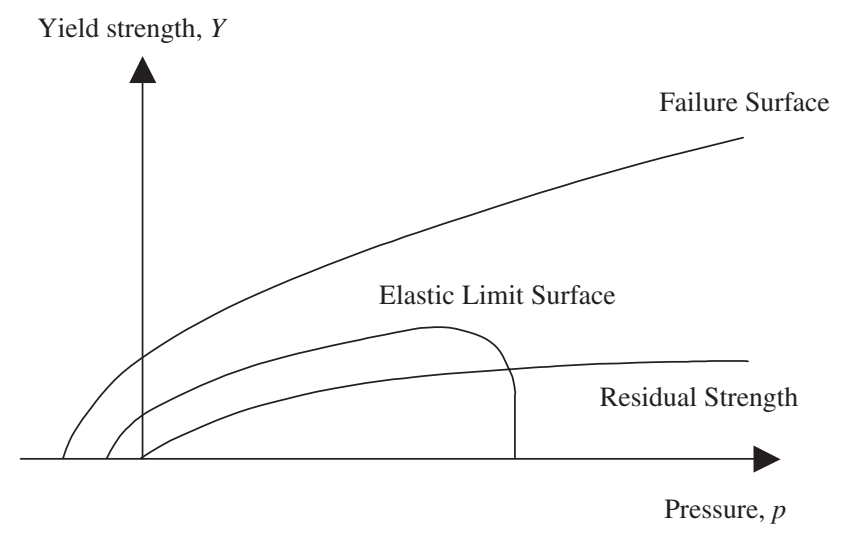

Fig. 1. The RHT constitutive model used for concrete [13].

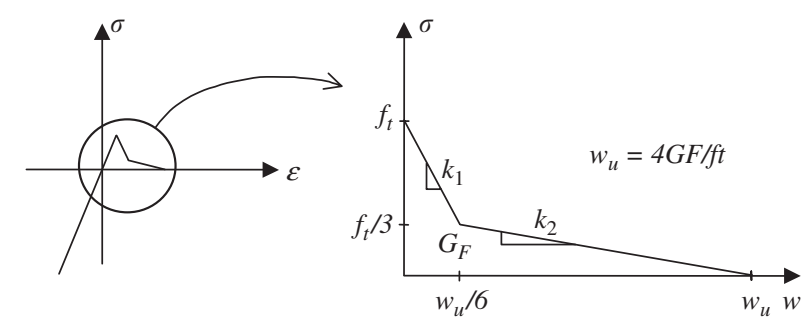

Fig. 2. Bi-linear uniaxial stress-crack opening relationship; based on Gylltoft [9].

\subsection{Modified crack softening law}

In AUTODYN, a linear softening law is included to model the post-failure response of concrete tension. However, concrete is a very brittle material and the strength decreases rapidly after the failure initiation; therefore a modified crack softening law is implemented in the numerical model. Hillerborg [8] originally presented a stepwise linear crack softening law. After Hillerborg published his work, there were several other proposals for the crack softening, for example Gylltoft [9] and Hillerborg [14]. The softening law chosen for this paper, proposed by [9] is based on the stress-crack opening relationship. To calculate the crack width $w_{\mathrm{u}}$ (when the stress has fallen to zero and a real crack has formed) the fracture energy, $G_{\mathrm{F}}$, and the tensile strength, $f_{\mathrm{t}}$, of concrete are used, as shown in Fig. 2. However, the AUTODYN model follows smeared crack approach, and consequently a stress-strain relation is used; the maximum cracking strain is calculated from the maximum crack opening as

$$
\varepsilon_{\mathrm{u}}=\frac{w_{\mathrm{u}}}{l}=\frac{4 G_{\mathrm{F}}}{f_{\mathrm{t}} l} .
$$

The crack width is smeared out over a distance, $l$. In two-dimensional models for un-reinforced concrete, this distance is normally approximated by the square root of the area of an element, see Johansson [15]. For three-dimensional models, the length is taken to be the third root of the volume of the element. The two slopes, $k_{1}$ and $k_{2}$ in Fig. 2, for the bi-linear crack softening law 
can be described by using Eq. (1)

$$
k_{1}=\frac{f_{\mathrm{t}}^{2}}{G_{\mathrm{F}}}, k_{2}=\frac{f_{\mathrm{t}}^{2}}{10 G_{\mathrm{F}}} .
$$

In AUTODYN the bi-linear crack softening law was implemented with subroutines. The predefined slope for linear crack softening was used. The linear softening slope is defined as

$$
k=\frac{f_{\mathrm{t}}^{2}}{2 G_{\mathrm{F}}} .
$$

When the tensile failure stress has been reached, the slopes, $k_{1}$ and $k_{2}$, can be described by using the predefined slope in AUTODYN

$$
\begin{aligned}
& k_{1}=2 k \text { for } \varepsilon \leqslant \frac{1}{6} \varepsilon_{\mathrm{u}}, \\
& k_{2}=\frac{2}{10} k \text { for } \varepsilon>\frac{1}{6} \varepsilon_{\mathrm{u}},
\end{aligned}
$$

where $\varepsilon$ is the cracking strain and $\varepsilon_{\mathrm{u}}$ is the ultimate cracking strain (when the stress has fallen to zero).

\subsection{Modified strain rate law for concrete in tension}

Concrete is very strain rate sensitive. In the CEB-FIB Model Code [10], there is a relationship for DIF (dynamic increase factor) for tension at varying strain rates. The DIF in the code is a design value, which means the increase in strength is given at a higher strain rate than in the experiments. Results presented in [11] show that the sudden increase in DIF for concrete in tension occurs at a strain rate of approximately $1 \mathrm{~s}^{-1}$. Fig. 3 shows a comparison of a proposed model [11] and the code [10]. The model fits the experimental data, as shown in the figure. The equations are [11],

$$
\begin{aligned}
& \frac{f_{\mathrm{ct}}}{f_{\mathrm{cts}}}=\left(\frac{\dot{\varepsilon}}{\dot{\varepsilon}_{s}}\right)^{\delta} \text { for } \dot{\varepsilon} \leqslant 1 \mathrm{~s}^{-1}, \\
& \frac{f_{\mathrm{ct}}}{f_{\mathrm{cts}}}=\beta\left(\frac{\dot{\varepsilon}}{\dot{\varepsilon}_{s}}\right)^{1 / 3} \text { for } \dot{\varepsilon}>1 s^{-1},
\end{aligned}
$$

where $f_{\text {ct }}$ is dynamic tensile strength at $\dot{\varepsilon}, f_{\text {cts }}$ is static tensile strength at $\dot{\varepsilon}_{\mathrm{s}}, f_{\text {ct } /} f_{\text {cts }}$ is the DIF (dynamic increase factor), $\dot{\varepsilon}$ is the strain rate in the range of $10^{-6}$ to $160 \mathrm{~s}^{-1}$,

$$
\begin{aligned}
\dot{\varepsilon}_{\mathrm{s}} & =10^{-6} \mathrm{~s}^{-1} \text { (static strain rate) } \\
\log \beta & =6 \delta-2 \\
\delta & =\frac{1}{1+\left(8 f_{\mathrm{c}}^{\prime} / f_{\mathrm{co}}^{\prime}\right)} \\
f_{\mathrm{co}}^{\prime} & =10 \mathrm{MPa} .
\end{aligned}
$$

In the RHT model the DIF for tension is determined by the parameter $\delta$, see [12]. Fig. 4 shows the DIF for two values of $\delta$. As seen in the figure, this parameter cannot be chosen in a way that fits 


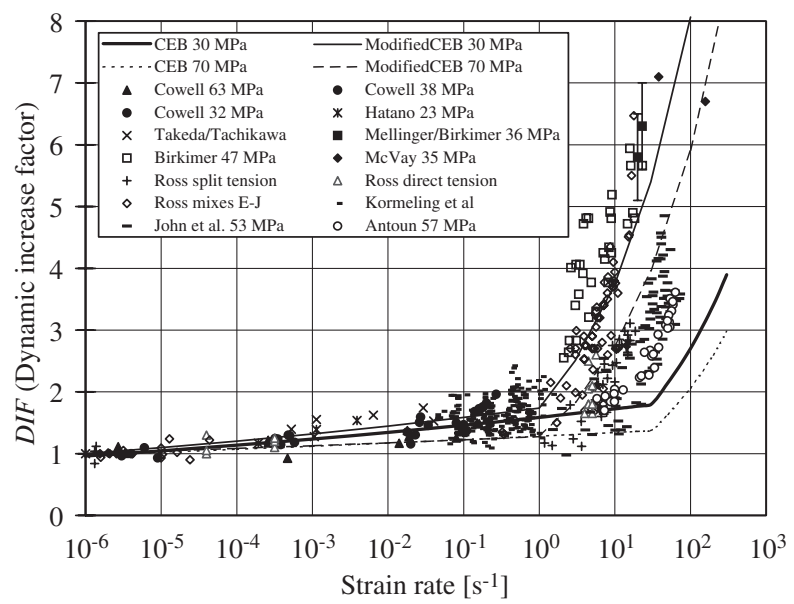

Fig. 3. Strain rate dependency for concrete in tension. Comparison of experimental data: the proposed model [11] (Modified CEB), and recommendations according to [10] (CEB); based on Malvar and Ross [11].

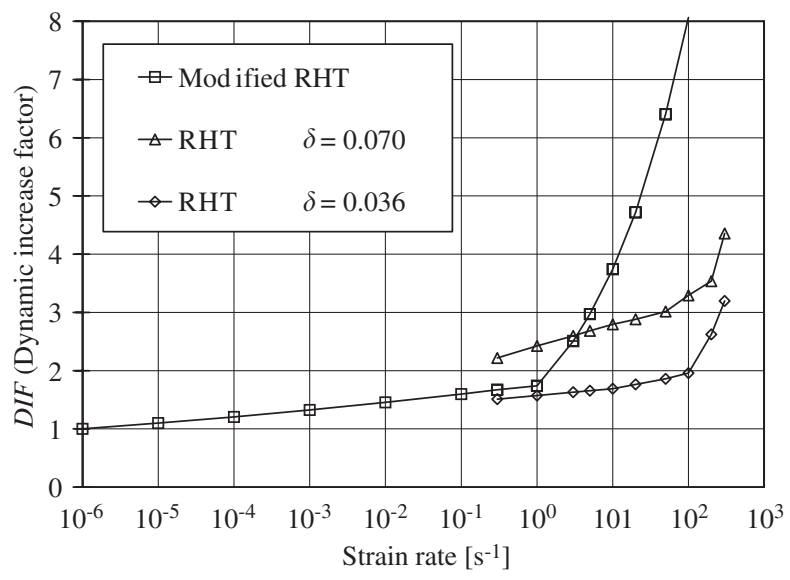

Fig. 4. The strain rate dependency for concrete in tension with the RHT model and the modified RHT model. $\delta$ is a strain rate parameter in the RHT model, see $[12,13]$.

the experimental data in Fig. 3. For this reason a strain rate law was implemented in the RHT model. In the RHT model the strain rate law was implemented as a stepwise linear by using subroutines in AUTODYN, for which the DIF relationship can be chosen by the user; in the figure the DIF chosen according to [11] is shown.

\section{Parametric studies}

Parametric studies were conducted with the modified RHT model to study the effects of the softening slope, the strain rate law, variations of the fracture energy and the tensile strength. The impact of a fragment on a disc-shaped concrete target with a diameter of $1 \mathrm{~m}$ and thickness of 
$140 \mathrm{~mm}$ at a velocity of $1163 \mathrm{~m} / \mathrm{s}$ was examined. The values are taken from an experiment analysed in Section 4 (example 3), and the material parameters used in the study are from the same example. The fragment and the concrete target were modelled by 2D axisymmetric model, and the fragment strikes the centre of the concrete disc.

When using a bi-linear softening slope, there was a minor difference in the damage in comparison with a linear softening slope, as shown in Fig. 5. In the analyses, bi-linear softening slope and the linear softening slope had the same fracture energy. The modified strain rate law was used. The depth of penetration was approximately the same for both analyses. However, due to the more brittle material behaviour in the bi-linear analyses, there was slightly more damage: the diameter of scabbing increased only by $2.0 \%$ and there were more cracks. The results indicate that the shape of the softening curve is less important for scabbing in concrete.

To study the effect of the strain rate law that was implemented in the RHT model, a comparison of the proposed model [11] and the code [10] was made. Results in Fig. 6 show that the cracking is reduced, and the diameter of scabbing is reduced by $11 \%$ when using the first model [11]. This is due to the increase in dynamic tensile strength.

To study the effect of the tensile strength three values of the static tensile strength, $0.05,0.071$ and 0.1 , of the mean value of the compressive strength were used. The results of the analyses show that the crack width increases when using lower static tensile strength, Fig. 7. Furthermore, for the highest tensile strength, the crack has not fully extended to the side opposite the impact.

To find the effect of fracture energy, it was varied between 85 and $205 \mathrm{Nm} / \mathrm{m}^{2}$, as shown in Fig. 8. It was found that the fracture energy has a minor effect on the depth of penetration and spalling. However, by increasing the fracture energy, scabbing and cracking were highly reduced.

\section{Comparison of the numerical model and experimental results}

To ensure that a numerical model can predict the depth of penetration, spalling and scabbing, results from several experiments with varying mass and impact velocities must be reproduced.
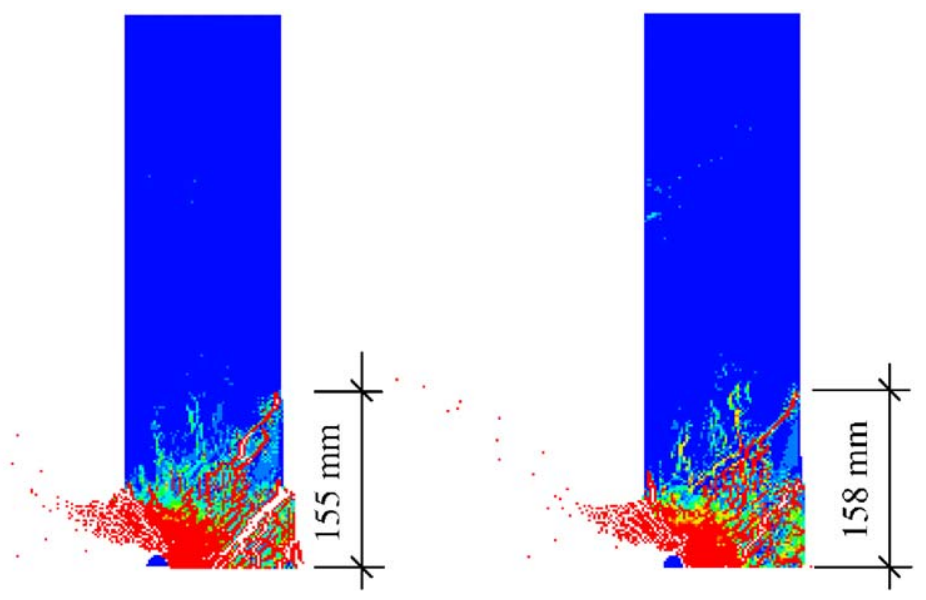

Fig. 5. Comparison of the effects of two crack-softening slopes. Left: Linear; Right: Bi-linear. 

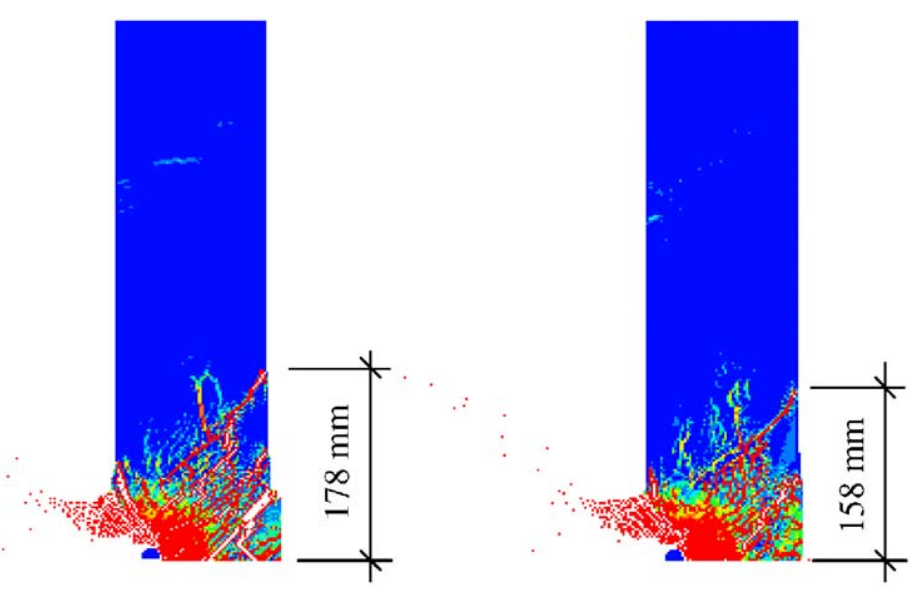

Fig. 6. Comparison of the effects of the strain rate law. Left: CEB-FIB [10]; Right: Malvar and Ross [11].

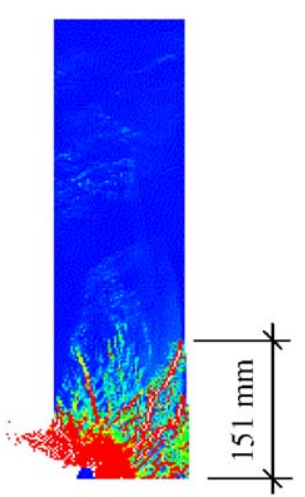

$f_{c t m}=0.05 f_{c m}$

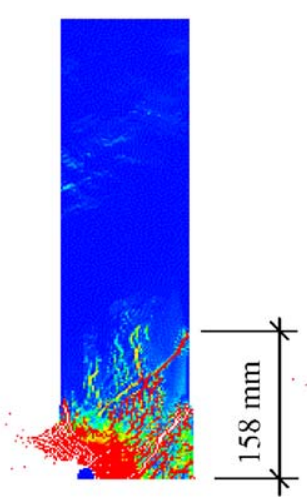

$f_{c m m}=0.071 f_{c m}$

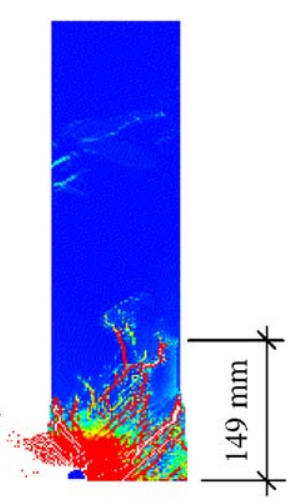

$f_{c t m}=0.1 f_{c m}$

Fig. 7. Comparison of the effects of three static tensile strengths; $f_{\mathrm{ctm}}=$ mean tensile strength and $f_{\mathrm{cm}}=$ mean compressive strength.

Here three series of experiments were analysed with the modified RHT model. The input data are given in Table 1, for more details of the model, see [12] and [13]. The first example is from Leppänen [16], the second from Hansson [17] and the third from Erkander and Pettersson [18].

In the first series [16] the experiments were conducted by shooting single fragments against concrete blocks. The dimensions of the blocks were $750 \times 375 \times 500 \mathrm{~mm}$, and the fragments were spherical with a radius of $4 \mathrm{~mm}$. The concrete had a cylinder strength of $31.2 \mathrm{MPa}$, tensile strength of $2.84 \mathrm{MPa}$, fracture energy of $84 \mathrm{Nm} / \mathrm{m}^{2}$ and the maximum aggregate size of $8 \mathrm{~mm}$. A total of eight shots were made with impact velocities varying from 1754 to $2000 \mathrm{~m} / \mathrm{s}$. Two or three shots were made for each block. The depth of penetration for the eight shots varied between 52 and $57 \mathrm{~mm}$, and the crater width varied from $74 \mathrm{~mm}$ up to $93 \mathrm{~mm}$. Although multiple fragments were shot against the concrete blocks, the results discussed in this paper are limited to single-fragment 


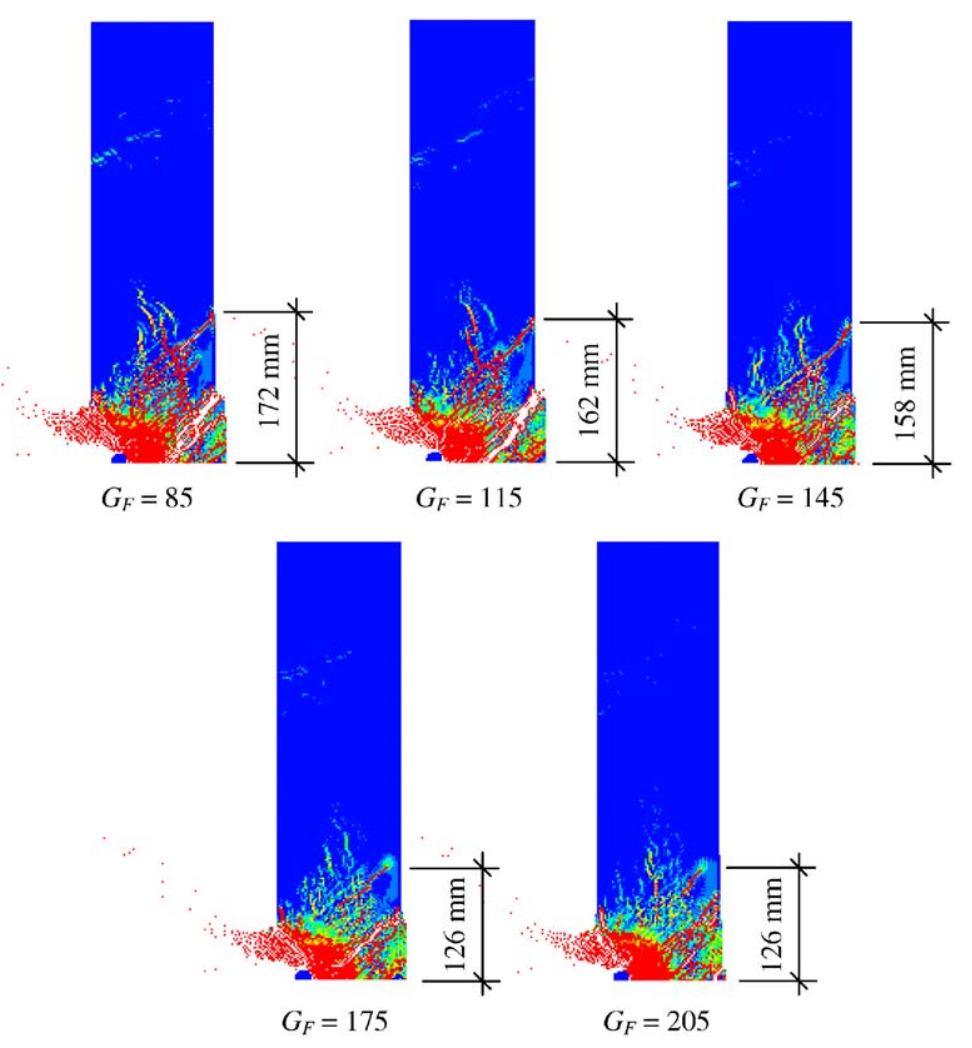

Fig. 8. Effects of variation in the level of fracture energy.

impacts. Information about the multiple fragment impacts may be found elsewhere [16]. A comparison of experiments and an analysis made with the material model, described in Section 2, are shown in Fig. 9; the block is cut in half, and a cross section is shown as well as the plane view of the fragment impacts. A magnification of the area of fragment impact is compared with a numerical analysis. For this shot, the impact velocity was recorded as $1879 \mathrm{~m} / \mathrm{s}$; the depth of penetration was $54 \mathrm{~mm}$ and the maximum crater diameter was $93 \mathrm{~mm}$. In the numerical analysis the depth of penetration was $52 \mathrm{~mm}$ and the maximum crater diameter was in good agreement. However, the tunnelling was not captured. For comparison, the true depth of penetration and the true crater diameter is also shown in the numerical result, see Fig. 9.

The second series analysed for experiments conducted by Hansson [17], in which a projectile impacts a concrete cylinder. The ogive-nose steel projectile used had a mass of $6.28 \mathrm{~kg}$, length of $225 \mathrm{~mm}$, diameter of $75 \mathrm{~mm}$, density of $7830 \mathrm{~kg} / \mathrm{m}^{3}$, bulk modulus of $159 \mathrm{GPa}$, shear modulus of $81.8 \mathrm{GPa}$, and yield stress of $792 \mathrm{MPa}$; the impact velocity was $485 \mathrm{~m} / \mathrm{s}$. The target was a concrete cylinder, cast in a steel culvert, with a diameter of $1.6 \mathrm{~m}$ and a length of $2 \mathrm{~m}$. The concrete cube strength was approximately $40 \mathrm{MPa}$ (tested on a $150 \mathrm{~mm}$ cube). The tensile strength and fracture energy were calculated according to CEB; tensile strength was $2.64 \mathrm{MPa}$ and fracture energy was $100 \mathrm{Nm} / \mathrm{m}^{2}$. Two shots were fired at the same impact velocity, the first with support and the 
Table 1

Input data in Autodyn for modelling concrete

\begin{tabular}{lll}
\hline Parameter & Value & Comments \\
\hline Shear modulus $(\mathrm{kPa})$ & $G$ & a \\
Compressive strength $f_{\mathrm{c}}(\mathrm{MPa})$ & $f_{\mathrm{c}}$ & $\mathrm{a}$ \\
Tensile strength $f_{\mathrm{t}} / f_{\mathrm{c}}$ & $0.071-0.091$ & $\mathrm{a}$ \\
Shear strength $f_{\mathrm{s}} / f_{\mathrm{c}}$ & 0.18 & (default) \\
Failure surface parameter $A$ & 2 & $\mathrm{~b}$ \\
Failure surface parameter $N$ & 0.7 & $\mathrm{~b}$ \\
Tens./compr.mMeridian ratio & 0.6805 & (default) \\
Brittle to ductile transition & 0.0105 & (default) \\
G(elas.)/G(elas-plas.) & 2 & (default) \\
Elastic strength $/ f_{\mathrm{t}}$ & 0.7 & (default) \\
Elastic strength $/ f_{\mathrm{c}}$ & 0.53 & (default) \\
Use cap on elastic surface & Yes & (default) \\
Residual strength const. $B$ & 1.8 & b,c and \\
Residual strength exp. $M$ & 0.7 & $\mathrm{~b}$ \\
Comp. strain rate exp. $\alpha$ & 0.032 & (default) \\
Tens. strain rate exp. $\delta$ & User-subroutine & d \\
Max. fracture strength ratio & $1 \times 10^{20}$ & (default) \\
Damage constant $D 1$ & 0.04 & (default) \\
Min. strain to failure & 0.01 & (default) \\
Residual shear modulus frac. & 0.13 & (default) \\
Tensile failure model & dser-subroutine & c \\
Erosion strain/instantaneous geometric strain (only for Lagrange) & 1.5 & \\
\hline
\end{tabular}

${ }^{\mathrm{a}}$ Material tests or calculated according to the [10].

${ }^{\mathrm{b}}$ Calculated with a model proposed by Attard and Setunge (1996).

${ }^{\mathrm{c} C}$ Calibrated by parametric studies.

${ }^{\mathrm{d}}$ RHT model without user-subroutine, $B=1.5$ and $\delta=0.025$ were used. The tensile failure model hydro was used.

second without support at the opposite side of the target. The depth of penetration was hardly influenced by the support: the difference was only $5 \mathrm{~mm}$. For the shot without support the depth of penetration was $655 \mathrm{~mm}$; for the second shot the depth of penetration was $660 \mathrm{~mm}$. The crater diameter in the experiment was approximately $800 \mathrm{~mm}$. In Fig. 10, a result from a numerical analysis is shown for a projectile striking a target without support on the opposite side. The depth of penetration was $643 \mathrm{~mm}$ and the maximum crater diameter was $780 \mathrm{~mm}$. Analysis with the RHT model was also conducted, the result is shown in the same figure. Detailed input for the analysis is published in [3].

In the third series tested with the model, experiments where scabbing occurred were analysed. Scabbing is caused by the reflected tensile stress wave; due to this it is important that the tensile behaviour be accurately described. In the experiments, which were conducted [18], single fragments were shot against concrete walls. The dimensions of the walls were $1000 \times 1000 \mathrm{~mm}$ with a thickness of $140 \mathrm{~mm}$, and the fragments were spherical with a radius of $10.3 \mathrm{~mm}$. The concrete has an average cube strength of $68.9 \mathrm{MPa}$ (tested on $150 \times 150 \mathrm{~mm}$ cubes). The tensile strength and fracture energy was calculated according to CEB; tensile strength 

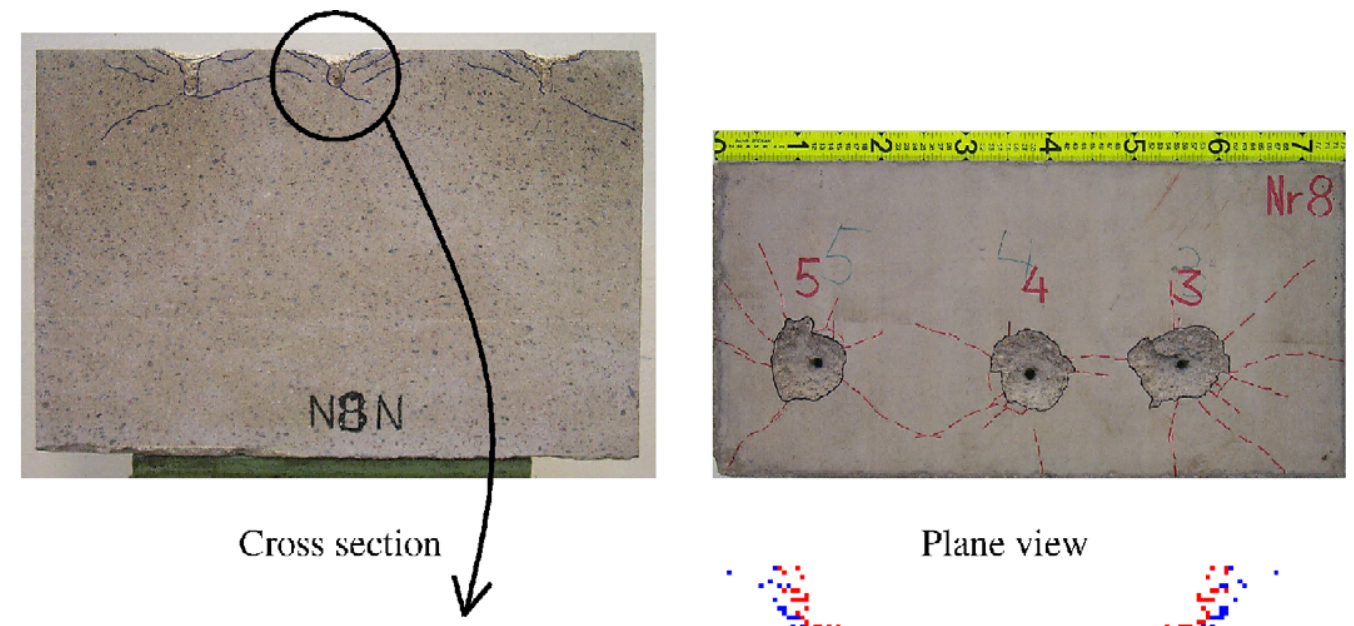

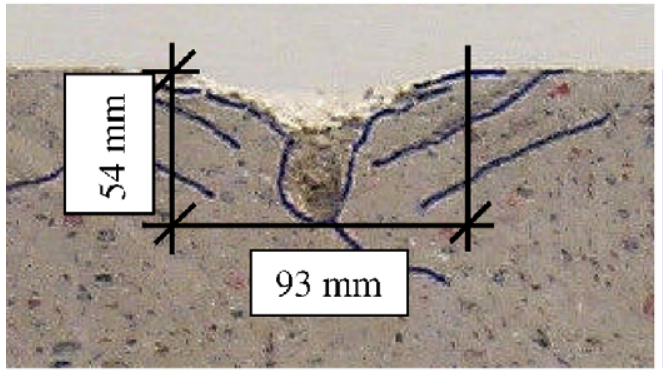

Experimental result

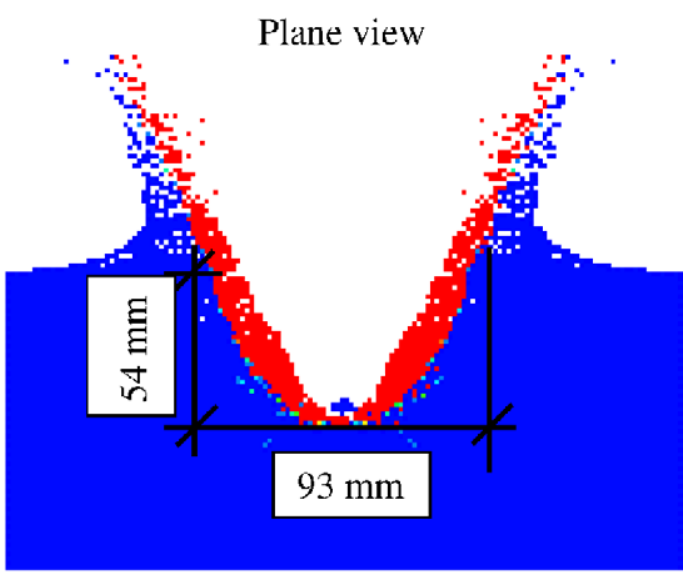

Numerical result

Fig. 9. Comparison of numerical result and experimental result. Experiments conducted by Leppänen [16].

was $4.14 \mathrm{MPa}$ and fracture energy was $145 \mathrm{Nm} / \mathrm{m}^{2}$. The results compared had impact velocities of $1024 \mathrm{~m} / \mathrm{s}, 1163 \mathrm{~m} / \mathrm{s}$ and $1238 \mathrm{~m} / \mathrm{s}$. The first shot analysed had a velocity of $1024 \mathrm{~m} / \mathrm{s}$ : the depth of penetration was $50 \mathrm{~mm}$, spalling diameter was $270 \mathrm{~mm}$ and the diameter of scabbing was $380 \mathrm{~mm}$. The second shot analysed had a velocity of $1163 \mathrm{~m} / \mathrm{s}$ : the depth of penetration was $66 \mathrm{~mm}$, spalling diameter was $240 \mathrm{~mm}$ and the diameter of scabbing was $310 \mathrm{~mm}$. Finally, the third shot analysed had a velocity of $1283 \mathrm{~m} / \mathrm{s}$ : the depth of penetration was $50 \mathrm{~mm}$, spalling diameter was $230 \mathrm{~mm}$ and the diameter of scabbing was $360 \mathrm{~mm}$. Numerical analyses with the modified RHT model are shown in Fig. 11, as well as results with the RHT model. The spalling was not accurately captured for the fragment impacts with velocities of $1024 \mathrm{~m} / \mathrm{s}$ and $1163 \mathrm{~m} / \mathrm{s}$. However, the scabbing was in good agreement with the experimental results. For the shot with a velocity of $1283 \mathrm{~m} / \mathrm{s}$, both the spalling and the scabbing diameter were in good agreement with the experimental result.

To sum up the third series, the deviation, in scabbing diameter, between experiments and numerical analyses with the RHT model was between 6 and 28\%, while with the modified RHT model the deviation was only between 2 and $10 \%$. 

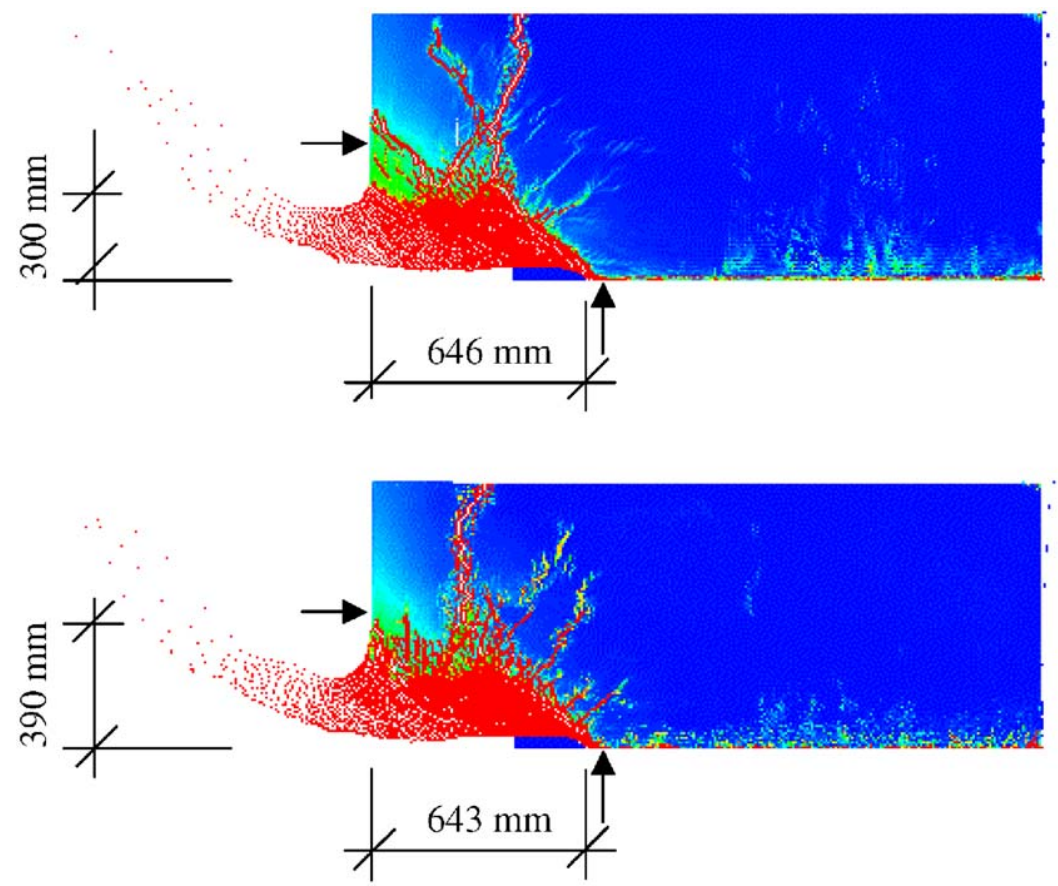

Fig. 10. Computed cratering and the depth of penetration of a projectile impact on a concrete cylinder. The arrows show the crater diameter and depth reported by Hansson [17]. Above: RHT model; Below: modified RHT model.

\section{Discussion}

In the parametric study, by increasing the fracture energy, as a consequence the maximum cracking strain increases and the consumed energy increases; and as a result the scabbing diameter decreases. However, the shape of the softening curve had a minor influence on the results, the consumed energy was approximately the same.

During the fragment penetration the strain rate varies in the concrete, and therefore it is important to have a model that realistically describes accurate tensile failure stress. For an example, for the proposed model [11] the tensile failure stress becomes more than two times higher than for the code [10] for the strain rate $10 \mathrm{~s}^{-1}$. Furthermore, the failure mode is influenced on the strain rate in tension, which can be seen Fig. 11, for the modified RHT model the crack propagation do not start at same location as for the RHT model.

To improve the accuracy in the simulations even further, more research must be done. In the simulations the tunnelling was not captured in one of the simulations, see Fig. 9; and the spalling was not accurate for the fragment impacts velocities of 1024 and $1163 \mathrm{~m} / \mathrm{s}$ as shown in Fig. 11. However, to incorporate the tensile behaviour accurately is a right step in improving the simulation technique for projectile and fragment impacts on concrete. 


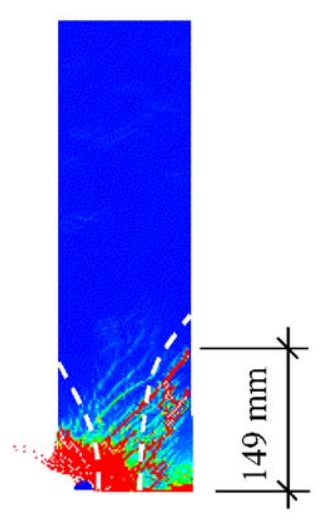

$$
v=1024 \mathrm{~m} / \mathrm{s}
$$
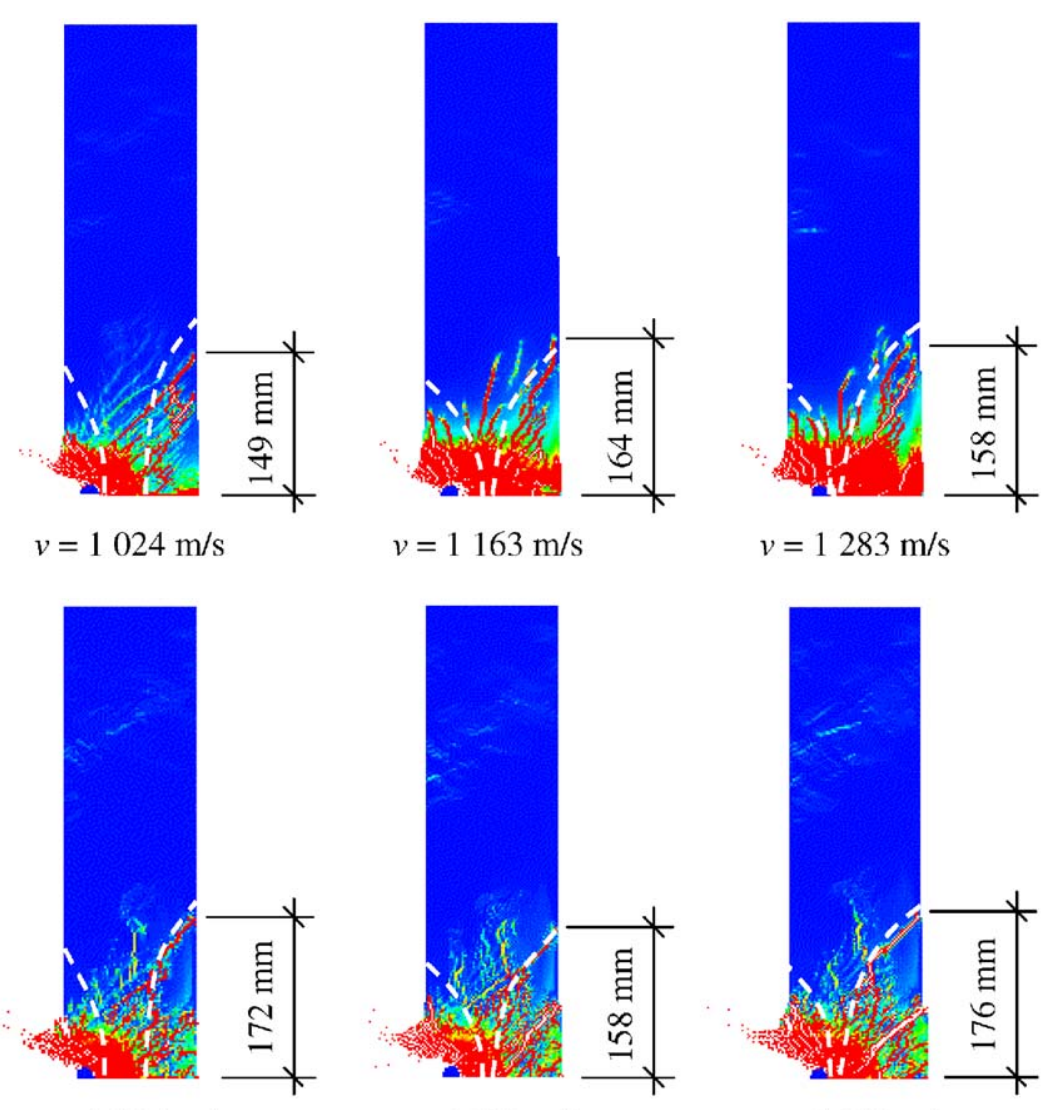

$$
v=1163 \mathrm{~m} / \mathrm{s}
$$

$$
v=1283 \mathrm{~m} / \mathrm{s}
$$
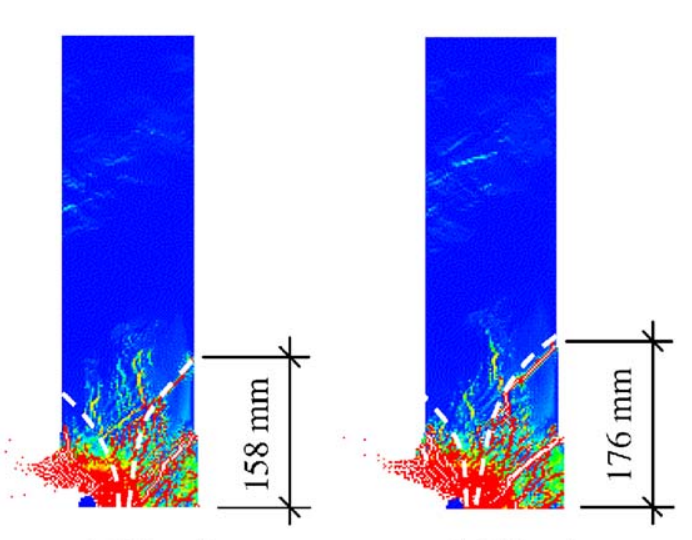

$$
v=1024 \mathrm{~m} / \mathrm{s}
$$

$$
v=1163 \mathrm{~m} / \mathrm{s}
$$

$$
v=1283 \mathrm{~m} / \mathrm{s}
$$

Fig. 11. Numerical analyses of fragment penetration, concrete spalling and scabbing. Dotted lines show craters reported by Erkander and Pettersson [18]. Above: RHT model; Below: modified RHT model.

\section{Summary and conclusions}

For projectile and fragment impacts, the velocity and the concrete strength, which depend on the pressure and the strain rate in compression, mainly influence the depth of penetration. However, cracking and scabbing are mainly influenced by the tensile strength, fracture energy and the strain rate in tension. For fragment impacts, spalling is caused by the direct impact due to crushing of the concrete. For projectile impacts, the spalling crater size also depends on the strain rate in tension as shown.

Parametric studies of fragment impacts were conducted. The crack width and scabbing increase with decreasing static tensile strength. By increasing the fracture energy, the cracking and scabbing were greatly reduced. However, this increase had a minor effect on the depth of penetration and spalling. Using a bi-linear softening law for tension increases the damage and the diameter of scabbing only slightly more than a linear one. Moreover, the scabbing was greatly influenced by the strain rate law. By using a DIF in tension, where the sudden increase in strength occurs at lower strain rates, the scabbing is decreased. 
The strain rate in tension for concrete depends on the projectile or fragment mass and the impact velocity. Thus, to predict the depth of penetration, spalling and scabbing, a material model that can accurately describe the DIF for tension must be used. To increase the accuracy of numerical analyses for both projectile and fragment impacts, a bi-linear crack softening law and a strain rate law were implemented in the RHT model in the software AUTODYN. It is also shown that the implementation gives results that are in good agreement with experimental results for the spalling, cracking and scabbing of plain concrete subjected to fragment and projectile impacts.

\section{Acknowledgements}

For the research presented in this paper financial support was obtained from the Swedish Rescue Services Agency. The author would like to thank his supervisor, the Head of the Department of Structural Engineering and Mechanics, Professor Kent Gylltoft, and members of the reference group for the project, "Dynamic behaviour of concrete structures subjected to blast and fragment impacts": Björn Ekengren, M.Sc., at the Swedish Rescue Services Agency, Mario Plos, Ph.D., at Chalmers University of Technology, and Morgan Johansson, Ph.D., at Reinertsen AB.

\section{References}

[1] Clegg RA, Sheridan J, Hayhurst CJ, Francis NJ. The application of SPH techniques in AUTODYN-2D to kinetic energy penetrator impacts on multi-layered soil and concrete targets. Eighth International Symposium on Interaction of the Effects of Munitions with Structures, 22-25 April 1997, VA, USA. 9pp.

[2] Johnson GR, Stryk RA, Beissel SR, Holmquist TJ. An algorithm to automatically convert distorted finite elements into meshless particles during dynamic deformation. Int J Impact Engng 2002;27(10):997-1013.

[3] Leppänen J. Dynamic Behaviour of concrete structures subjected to blast and fragment impacts. Licentiate Thesis, Department of Structural Engineering, Concrete Structures, Göteborg, Sweden: Chalmers University of Technology, 2002. 71pp.

[4] Leppänen J. Experiments and numerical analyses of blast and fragment impacts on concrete. Int J Impact Engng 2005;31(7):843-60.

[5] Rempling R. Concrete wall subjected to fragment impacts: Numerical analyses of perforation and scabbing. Department of Structural Engineering and Mechanics, Concrete Structures, Master's thesis nr. 04:1, Göteborg, Sweden: Chalmers University of Technology, 2004. 55pp.

[6] Papados PP. A reinforced concrete structure under impact: Response to high rate loads. In: Jones N, Brebbia CA, editors. Sixth International Conference on Structures Under Shock and Impact VI. Southampton: WIT Press; 2000. p. $501-10$.

[7] Ågårdh L, Laine L. 3D FE-simulation of high-velocity fragment perforation of reinforced concrete slabs. Int J Impact Engng 1999;22(9):911-22.

[8] Hillerborg A. Analysis of fracture by means of the fictitious crack model, particularly for fibre reinforced concrete. The Int J Cement Composites 1980;2(4):177-84.

[9] Gylltoft K. Fracture mechanics models for fatigue in concrete structures. Doctoral Thesis, Division of Structural Engineering, Luleå University of Technology, Luleå, Sweden, 1983. 210pp.

[10] CEB-FIB Model Code 1990. Design Code. Lausanne, Switzerland: Thomas Telford; 1993 437pp.

[11] Malvar LJ, Ross CA. Review of strain rate effects for concrete in tension. ACI Materials J 1998;95(6):735-9.

[12] AUTODYN Manuals. Version 5, Concord, CA, USA: Century Dynamics, Inc. 2004. 
[13] Riedel W. Beton unter dynamischen Lasten Meso- und makromechanische Modelle und ihre Parameter (in German). Doctoral Thesis, der Bundeswehr Munchen, Freiburg, Germany: Institut Kurzzeitdynamik, ErnstMach-Institut, 2000. 210pp.

[14] Hillerborg A. The theoretical basis of a method to determine the fracture energy $G_{F}$ of concrete. Rilem Technical Committees 1985;18(106):291-6.

[15] Johansson M. Structural behaviour in concrete frame corners of civil defence shelters, non-linear finite element analyses and experiments. Doctoral Thesis, Department of Structural Engineering, Concrete Structures, Göteborg, Sweden: Chalmers University of Technology, 2000. 204pp.

[16] Leppänen J. Splitterbelastad betong, Experiment och numeriska analyser (In Swedish). Fragment impacts on concrete: Experiments and numerical analyses. Department of Structural Engineering and Mechanics, Concrete Structures, Report nr. 03:6, Göteborg, Sweden: Chalmers University of Technology, 2003. 74pp.

[17] Hansson H. Numerical simulation of concrete penetration. FOA report 98-00816-311-SE, Defence research establisment, Tumba, Sweden, 1998, 17pp.

[18] Erkander $\AA$, Pettersson L. Betong som splitterskydd: Skjutförsök på plattor av olika betongmaterial (in Swedish). (Concrete as a protective barrier against fragment impacts: Fragment impacts on plates made of different concretes. FOA report C 20574-D6(D4), Stockholm, Sweden: Swedish Defence Research Agency, 1985. 66pp. 